\title{
Ectopic expression of Mn-SOD in Lycopersicon esculentum leads to enhanced tolerance to salt and oxidative stress
}

\author{
Yueju Wang ${ }^{A *}$, Michael WisniewskiB* *, Richard Meilanc, Sandra L. Uratsu', Minggang Cui, \\ Abhaya Dandekar' and Leslie Fuchigami ${ }^{\mathrm{A}}$
}

${ }^{A}$ Department of Horticulture, Oregon State University, Corvallis, OR, 97331- 7304, USA; ${ }^{B}$ USDA-ARS, 45 Wiltshire Road, Kearneysville, WV, 25430-9606, USA, 'CForestry \& Natural Resource Department, Purdue University, West Lafayette, IN, 47907-2072, USA, Department of Pomology, University of California, Davis, CA 95616-8683, USA; *Current address: Children's Blood Foundation Laboratories, Weill Medical College of Cornell University, New York, NY 10021, USA.

*Email: kew2010@med.cornell.edu.**Corresponding author,Email: michael.wisniewski@ars.usda.gov

\begin{abstract}
Production of reactive oxygen species (ROS) is associated with a number of physiological disorders in plants. Superoxide dismutase (SOD) catalyzes the breakdown of superoxide $\left(\mathrm{O}_{2}^{-}\right)$into $\mathrm{O}_{2}$ and $\mathrm{H}_{2} \mathrm{O}_{2}$ and provides the first line of defense against the toxic effects of elevated levels of ROS. The effect of increased expression of Mn superoxide dismutase (Mn-SOD) on salt stress tolerance was studied using transformed tomato (Lycopersicon esculentum cv. Zhongshu No. 5) plants. Northern blots confirmed expression of the heterologous Mn-SOD in transgenic plants. Strong Mn-SOD enzyme activity was detected by native PAGE in transformed plants. Transgenic plants showed resistance to the superoxide-generating herbicide methyl viologen (MV, $\left.10^{-4} \mathrm{M}\right)$. The total SOD activity was one and one half- to two-fold higher, and APX (ascorbate peroxidase) activity was six to seven fold higher in transgenic, than in wild-type (WT) plant under MV stress. Germination of transgenic tomato seeds at a $\mathrm{NaCl}$ concentration of $150 \mathrm{mM}$ was greater than wild-type seeds. When exposed to salt stress, roots of transgenic plants were less stunted and leaf injury was lower than that observed in WT plants. Also, the total APX activity of transgenic plants was 4 to 5 fold higher than that of WT under $\mathrm{NaCl}(200 \mathrm{mM})$ stress.
\end{abstract}

Key words: Superoxide dismutase, oxidative stress, salt stress, transgenic tomato.

\section{Introduction}

Salt stress is one of the most common types of abiotic stress that limits the production of agricultural plants around the world ( $\mathrm{Zhu}$, 2000). Plants subjected to salt stress also show elevated levels of activated forms of oxygen and free radicals. These elements often are associated with damage to membranes and essential macromolecules such as protein, DNA, and lipids (Fadzilla et al., 1997; Gueta-Dahan et al., 1997; Hernández et al., 1995).

Superoxide dismutase (SOD) is an important enzyme in a plant's defense against oxidative stress. It catalyzes the conversion of two superoxide anions $\left(\mathrm{O}_{2}^{-}\right)$into hydrogen peroxide $\left(\mathrm{H}_{2} \mathrm{O}_{2}\right)$ and $\mathrm{O}_{2}$ and alleviates oxidative stress (Bowler et al., 1992). SODs are a group of metal-containing enzymes and are classified into three types according to their metal cofactor requirements: iron $\mathrm{SOD}$ (Fe-SOD) is localized in the chloroplast; copper-zinc SOD $(\mathrm{Cu} / \mathrm{Zn}-\mathrm{SOD})$ is localized in the chloroplast, cytosol, and possibly the extracellular space; and manganese SOD (Mn-SOD) is found mainly in mitochondria and peroxisomes (Alscher et al., 2002).

Antioxidant enzyme activity is found in plants responding to various environmental and chemical stresses (Allen, 1995; Baek et al., 2006), such as freezing (Martinez et al., 2001), chilling (Baek and Skinner, 2005; Iannelli et al., 1999), salt (Gueta-Dahan et al., 1997; Hernández et al., 1995; Rajguru et al., 1999), and methyl viologen (MV) (Bowler et al., 1991; Donahue et al., 1997).

The role of SOD during salt stress has received much attention. Exposure of salt-tolerant pea plants to $\mathrm{NaCl}$ resulted in the formation of $\mathrm{O}_{2}^{-}$and $\mathrm{H}_{2} \mathrm{O}_{2}$ and increased the activity of $\mathrm{SOD}$ and other antioxidant enzymes, such as ascorbate peroxides (APX). Transcripts levels for Mn-SOD, $\mathrm{Cu} / \mathrm{Zn}-\mathrm{SOD}$, and APX were strongly induced in the salt-tolerant variety but not in the saltsensitive one (Hernández et al., 2000). Reports dealing with rice (Dionisio-Sese and Tobita, 1998) and tomato plant (Shalata et al., 2001), have also reported increased SOD activity in salt-tolerant cultivars when exposed to salt stress. Additionally, Tanaka et al. (1999) confirmed that overexpression of a yeast $M n-S O D$ gene in rice confers tolerance to salt stress.

Enhanced expression of SODs in transgenic plants has demonstrated tolerance to MV (Allen, 1995; Perl et al., 1993), freezing (McKersie et al., 1999), and salt (Tanaka et al., 1999). In order to further understand the role of APX and SOD in response to oxidative stress induced by abiotic stresses, transgenic tomato plants were produced that overexpress either cAPX (Wang et al., 2005 and 2006) or Mn-SOD and their response to several abiotic stresses was evaluated. The purpose of this study was to evaluate the tolerance of transgenic $M n-S O D$ tomato plants to salt $(\mathrm{NaCl})$ and oxidative (MV) stress.

\section{Materials and methods}

Generation and analysis of transgenic tomato plants: Mn-SOD cDNA was synthesized from rubber tissue (Hevea brasiliensis) based on primers by Miao and Gaynor (1993). The cDNA was mobilized into the binary vector pDU92.3103 (Tao et al., 1995 ) between the cauliflower mosaic virus $35 \mathrm{~S}$ promoter and 
terminator regions. The construct, pDU96.2144, contained the $\beta$-glucuronidase (GUS) reporter gene and the NPTII selectable marker, and was transferred into the tomato (Lycopersicon esculentum cv. Zhongshu No. 5) genome via the Agrobacterium tumefaciens-mediated transformation method described by Frary and Earle (1996) with modifications by Wang (2005). The kanamycin-resistant transformants were screened by the GUS histochemical staining assay according to the method developed by Jefferson et al. (1987). Genomic DNA was isolated from wildtype (WT) and $M n$-SOD-overexpressing plants $\left(\mathrm{T}_{1}\right)$, according to the procedure of Doyle and Doyle (1987).

PCR reaction used the $35 \mathrm{~S}$ promoter forward primer and rubber $M n-S O D$-specific reverse primer (Miao et al., 1993). The sequences for the forward and reverse primers for $35 \mathrm{~S}:: \mathrm{Mn}$ $S O D$ included 5'-CACGTCTTCAAAGCAAGTGG -3' and 5'-CTAAGAAGAAGGGCATTCTTTGGCAT -3', respectively. About 20 ng DNA was used for the PCR reaction, under the following conditions: $1 \mathrm{~min}$ at $94^{\circ} \mathrm{C}, 1 \mathrm{~min}$ at $60^{\circ} \mathrm{C}$, and $2 \mathrm{~min}$ at $72^{\circ} \mathrm{C}$ for 30 cycles.

Mn-SOD expression was assayed by northern analysis and SOD activity gel assay. Wild-type (WT) and transgenic plants were grown in a greenhouse under natural lighting supplemented with sodium vapor lamps (1000W, Philips, Inc., Eindhoven, Netherlands) for a $16-\mathrm{h}$ photoperiod at approximately $23 / 21^{\circ} \mathrm{C}( \pm$ $2^{\circ} \mathrm{C}$, day/night temperature). Seedlings were grown in a potting mix containing peat moss (Premier Horticulture, Inc., Quebec, Canada). $T_{1}$ seeds obtained by self-pollination of each of $T_{0}$ plants were screened for resistance to kanamycin. $T_{2}$ seeds were obtained from individual $\mathrm{T}_{1}$ plants by self-pollination and were used to generate $T_{2}$ transgenic progeny. All the transgenic plants were resistant to the kanamycin.

Northern Blot assay: Total RNA was extracted from leaves of transgenic and WT plants using Tri-reagent (Molecular Research, Inc.). $30 \mu \mathrm{g}$ of total RNA from each sample was used for northern blot assay. The hybridization procedure was as described by Super Hyb kit (Molecular Research, Inc., Cincinnati, OH). The hybridization probe was a ${ }^{32} \mathrm{P}$-labeled Mn-SOD PCR fragment. RNA hybridization was detected using a PhosphorImager SI (Molecular Dynamics Inc., Sunnyvale, CA).

APX and SOD gel activity assay: About $100 \mathrm{mg}$ of leaf tissue was ground to a fine powder in liquid nitrogen and homogenized in $200 \mu$ of APX activity gel grinding buffer $\left[100 \mathrm{mM} \mathrm{NaPO}_{4}(\mathrm{pH}\right.$ 7.0), $5 \mathrm{mM}$ ascorbate, $1 \mathrm{mM}$ EDTA (pH 8.0), 10\% glycerol, and $0.001 \%$ bromophenol blue] and SOD activity gel grinding buffer [50 mM Tris (pH 6.8), 10\% glycerol, and $0.001 \%$ bromophenol blue], respectively. The supernatant was collected and protein concentration was determined using a Protein Assay system (Bio-Rad, Hercules, CA). $70 \mu \mathrm{g}$ of total protein was loaded into each lane of a native PAGE gel. APX gel activity analysis was conducted as described by Mittler and Zilinska (1993). The SOD gel activity assay was described by Payton et al. (1997). After staining, the gels were scanned with a Densitometer Scanner I (Molecular Dynamics, Inc., Cincinnati, $\mathrm{OH}$ ). The bands were analyzed using ImageQuant 5.2 software (Molecular Dynamics, Inc., Cincinnati, OH).

Application of methyl viologen: Shoots were treated with methyl viologen (MV, Sigma) following the procedure described by Perl et al. (1993). Shoot cuttings (with three to four leaves) from WT and $\mathrm{T}_{0}$ transgenic plants were obtained from containerized mature plants grown in the greenhouse. The cut end of the shoots was placed in $10^{-4} \mathrm{M} \mathrm{MV}$. After $16 \mathrm{~h}$, the cut ends were transferred to tap water for an additional two days. Two leaf discs (1.02 $\mathrm{cm}$ in diameter) of the third leaf from the apex were excised after the MV treatment, and MV-induced oxidative damage was evaluated using the leaf electrolyte leakage (Wisniewski et al., 1997) with a conductivity meter (Markson Science, Inc., Del Mar, CA). Means for all values were an average of two subsamples in each plant with three replications. The data were subjected to Duncan's multiple range test (NCSS-PASS software, NCSS Inc., Williamsport, PA). Arcsine square root transformations were performed before data analysis; nontransformed means are presented. MV treated leaf discs were also sampled and stored at $-80^{\circ} \mathrm{C}$ prior to APX and SOD analyses.

Salt Stress: To evaluate salt stress, seeds from WT and $T_{1}$ plants were placed in petri dishes $(\approx 40$ seeds per box $)$ on filter paper (Whatman 3MM) saturated with $150 \mathrm{mM} \mathrm{NaCl}$ solution. They were germinated at $23 / 21^{\circ} \mathrm{C}\left( \pm 2{ }^{\circ} \mathrm{C}\right.$, day/night temperature $)$ under cool white fluorescent lights $\left(100-150 \mu \mathrm{mol} \mathrm{m}^{-2} \mathrm{sec}^{-1}\right)$ using a 16-h photoperiod. At the end of two weeks, germination was measured. Germination was considered successful when the radicle protruded through the seed coat. Values are means $\pm \mathrm{SE}$ (three repeats). The data were subjected to Duncan's multiple range test.

To evaluate the tolerance of developing roots to salt stress, shoot cuttings from 10-day-old WT and $\mathrm{T}_{2}$ seedlings were grown in sterile, solidified Murashige-Skoog (MS; Murashige and Skoog, 1962) medium (Sigma) amended with either $200 \mathrm{mM}$ or $250 \mathrm{mM}$ $\mathrm{NaCl}$. After 5 weeks at $23 / 21^{\circ} \mathrm{C}\left( \pm 2^{\circ} \mathrm{C}\right.$, day/night temperature $)$, the fresh roots were excised, blotted on filter paper, and weighed. Values are means \pm SE (six replicates). The data were subjected to Duncan's multiple range test.

WT and $\mathrm{T}_{2}$ shoot cuttings were grown in rooting medium for 2 weeks. Healthy seedlings were transferred to $5.8 \times 5.8 \times 8$-cm plastic pots with peat moss soil and watered with tomato fertilizer (9N-4.4P-12.5K, Schultz, Inc., Bridgeton, MO) for one week. Stress was imposed by watering plants with tomato fertilizer and $\mathrm{NaCl}(200 \mathrm{mM}$ or $250 \mathrm{mM})$ solution every three days. Controls received only fertilizer. The plants were maintained in a greenhouse with natural lighting supplemented with sodium vapor lamps (1000W, Philips, Inc., Eindhoven, Netherlands) for 16-h photoperiod at approximately $23 / 21^{\circ} \mathrm{C}\left( \pm 2^{\circ} \mathrm{C}\right.$, day/night temperature). Height (from the apex to soil) was measured after 10 days (d). The extent of injury was evaluated visually at 10 , 20 , and $30 \mathrm{~d}$ following treatment. The scale was as follows: 0 , no injury; 1 , slow growth but no obvious damage, $\leq 20 \%$ leaf area exhibited injury; 2, leaves turned yellow, 21 to $40 \%$ of the leaf area injured; 3 , plants wilted, 41 to $60 \%$ leaf area injured; 4 , seriously damaged, the plant became soft and could not remain upright, 61 to $80 \%$ leaf area injured; 5,81 to $100 \%$ leaf area injured or plant died. Mean values of 5 replicates were calculated and the ranks were subjected to the non-parametric Kruskal-Wallis test. The leaf discs from WT and transgenic plants grown for $10-\mathrm{d}$ under $\mathrm{NaCl}$ $(200 \mathrm{mM})$ stress were then frozen in liquid nitrogen and stored at $-80^{\circ} \mathrm{C}$ for further enzyme activity gel analyses. 


\section{Results}

Overexpression of the Mn-SOD gene: No detectable GUS activity was seen in WT leaves. Transgenic leaves stained intensely blue, indicating high levels of GUS activity. No PCR products could be amplified from WT plants, whereas products of the expected size $(\approx 800 \mathrm{bp}$ ) were amplified from all transgenic lines (date not shown). Northern-blot analysis was performed to assess the mRNA levels in transgenic plants. All the transgenic plants contained transcripts but levels among individual lines varied. WT plants did not exhibit transcript that hybridized to the probe (Fig. 1). Two transgenic lines, S4 and S20, were selected for further study because they showed higher expression levels.

The selected transgenic lines were screened by gel assay for the presence of Mn-SOD activity. Two isoforms were observed in all plants, and may represent chloroplastic (chl) and cytosolic (cyt) $\mathrm{Cu} / \mathrm{Zn}-\mathrm{SOD}$ (Perl et al., 1993). Transgenic plants displayed an additional lower mobility band corresponding to the Mn-SOD enzyme activity (Fig. 2A). Total APX activity was also measured.

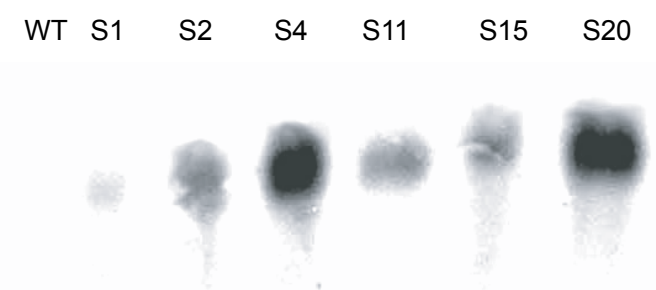

Fig.1. Northern blot analysis of RNA isolated from the $\mathrm{T}_{1}$ plants. $30 \mu \mathrm{g}$ of total RNA was used per lane for each blot. Blots were probed with ${ }^{32}$ P-labeled Mn-SOD PCR products. WT, wild-type plant; S1 to S20, independent transgenic lines.
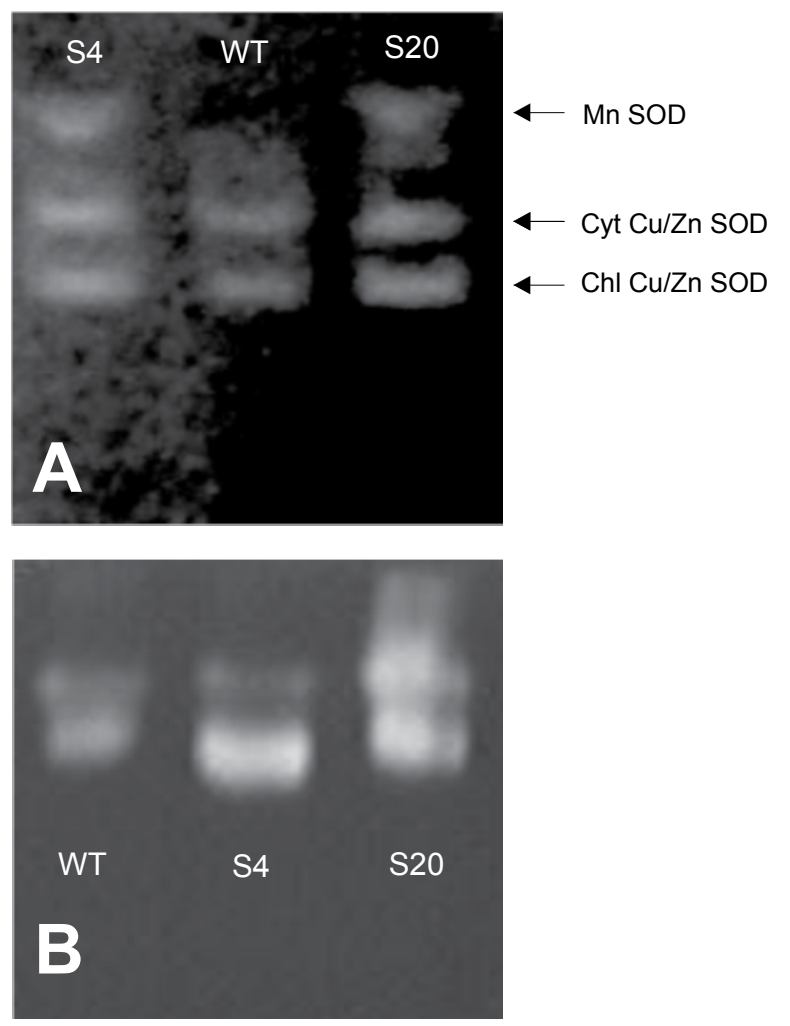

Fig. 2. Detection of (A) SOD and (B) APX activity in leaves of wild-type (WT) and transgenic Mn-SOD (Lines S4, S20) tomato plants. About 70 $\mu \mathrm{g}$ protein was loaded on the non-denaturing polyacrylamide gel.

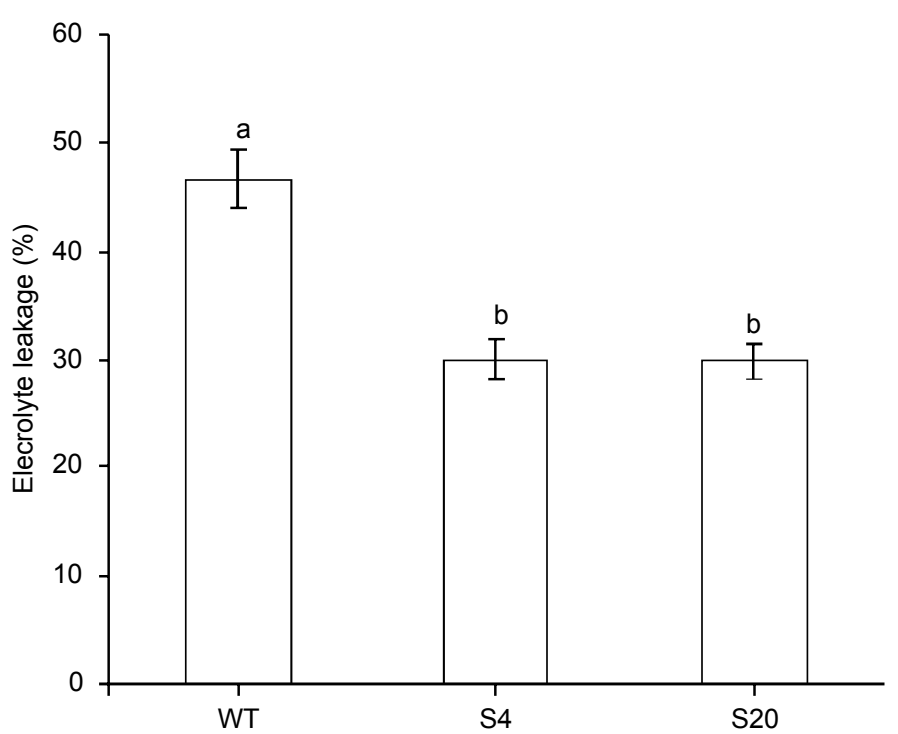

Fig. 3. Effects of methyl viologen $\left(10^{-4} \mathrm{M}\right)$ stress on electrolyte leakage from transgenic Mn-SOD (Lines S4, S20) and wild-type (WT) tomato plants. Bars represent SE for three replicates. Different letters indicate significant differences $(P<0.05)$ between means (Duncan's multiple range test).

Lines S4 and S20 exhibited 2- to 3-fold higher APX activity than in WT plants (Fig. 2B).

Effects of MV stress: Methyl viologen-induced electrolyte leakage in transgenic plants was significantly less than in WT $(P<0.05$, Fig. 3). Mean electrolyte leakage in WT leaves was about 47\%. In comparison, Mn-SOD-expressing lines (S4, S20) had significantly lower electrolyte leakage (approximately, 30\%). After two days under MV treatment, total SOD activity was 1.5to 2-fold higher in transgenic plants. APX activity of transgenic plants was 6- to 7-fold higher than WT plants following MV treatment (data not shown).

Effects of NaCl stress: The effect of $150 \mathrm{mM} \mathrm{NaCl}$ on the percent seed germination at 13 days was 76 and $81 \%$ germination for transgenic line S20 and S4, respectively and 39\% for WT seeds (Fig. 4). After 5 weeks of treatment, the fresh root weight of transgenic plant (14 $\mathrm{g}$ and $8 \mathrm{~g}$ for S4; $14 \mathrm{~g}$ and $7 \mathrm{~g}$ for S20) was significantly $(P<0.05)$ greater than that of WT $(8 \mathrm{~g}$ and $2 \mathrm{~g})$ tomato plants at $200 \mathrm{mM}$ and $250 \mathrm{mM} \mathrm{NaCl}$, respectively (Fig. 5). Irrigation of transgenic and WT tomato plants with $200 \mathrm{mM}$

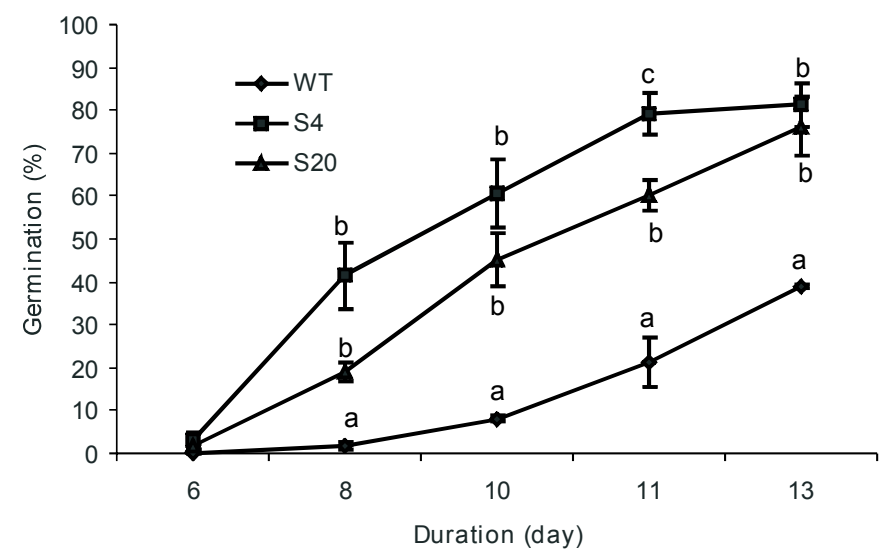

Fig. 4. Germination in $\mathrm{T}_{2}$ transgenic Mn-SOD (Lines S4, S20) and wildtype tomato seeds treated with $\mathrm{NaCl}(150 \mathrm{mM})$ for various periods of time. Values are means $\pm \mathrm{SE}(\mathrm{n}=3)$. Different letters indicate significant differences $(P<0.05)$ between means within each sampling time (Duncan's multiple range test). 


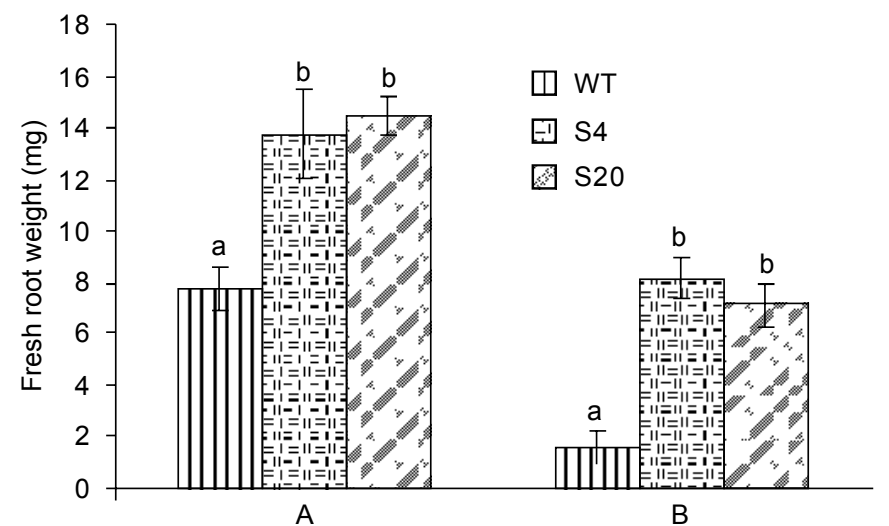

Fig. 5. Effects of $200 \mathrm{mM}$ (A) or $250 \mathrm{mM}$ (B) NaCl treatments on root development of wild-type (WT) and transgenic Mn-SOD (Lines S4, S20) tomato plants. Fresh weight was determined 5 weeks after the treatment. Values are means $\pm \mathrm{SE}(\mathrm{n}=6)$. Different letters indicate significant differences $(P<0.05)$ between means within each $\mathrm{NaCl}$ treatment level (Duncan's multiple range test).

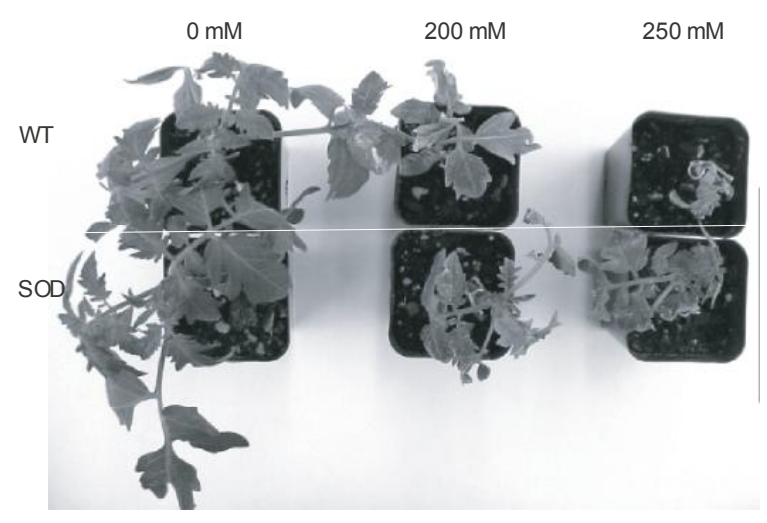

Fig. 6. Effects of salt stress on wild-type (WT) and transgenic Mn-SOD (Line S20) tomato plants. Plants were treated with $200 \mathrm{mM}$ and $250 \mathrm{mM}$ $\mathrm{NaCl}$ for $18 \mathrm{~d}$ in the greenhouse.

and $250 \mathrm{mM} \mathrm{NaCl}$ solution severely inhibited their shoot height growth (Fig. 6). The margins of leaflets in WT plants became necrotic following 10 days of salt treatment. Visible injury to WT was rated as 2.2. In contrast, injury to transgenic plants was significantly lower $(P<0.05)$, showing only slight leaf area injury (scale 1). The effect of the salt treatment was still apparent but severe after $20 \mathrm{~d}$. WT plants displayed visible necrotic injury (scale 3.6) after $20 \mathrm{~d}$. In contrast, the transgenic seedlings showed less injury (Fig. 7A). At $250 \mathrm{mM} \mathrm{NaCl}$, WT seedlings showed injury scale 5 after $20 \mathrm{~d}$, whereas the transgenic plants exhibited less wilting injury (average scale 2.2 for S4 and 3 for S20). The differences in visible injury between transgenic and WT plants were statistically significant $(P<0.05$, Fig. 7B). The leaf APX activity in transgenic plants was about 4- to 5-fold higher than that in WT plants after $10 \mathrm{~d}$ of $\mathrm{NaCl}(200 \mathrm{mM})$ treatment (data not shown).

\section{Discussion}

Numerous studies have indicated that oxidative stress enhances SOD activity (Donahue et al., 1997; El-Saht, 1998). Abiotic stresses, such as chilling, drought, and salt stress have been correlated with increase in SOD activity (Baek et al., 2006; Dionisio-Sese and Tobita, 1998; Fadzilla et al., 1997; Scandalios, 1993).
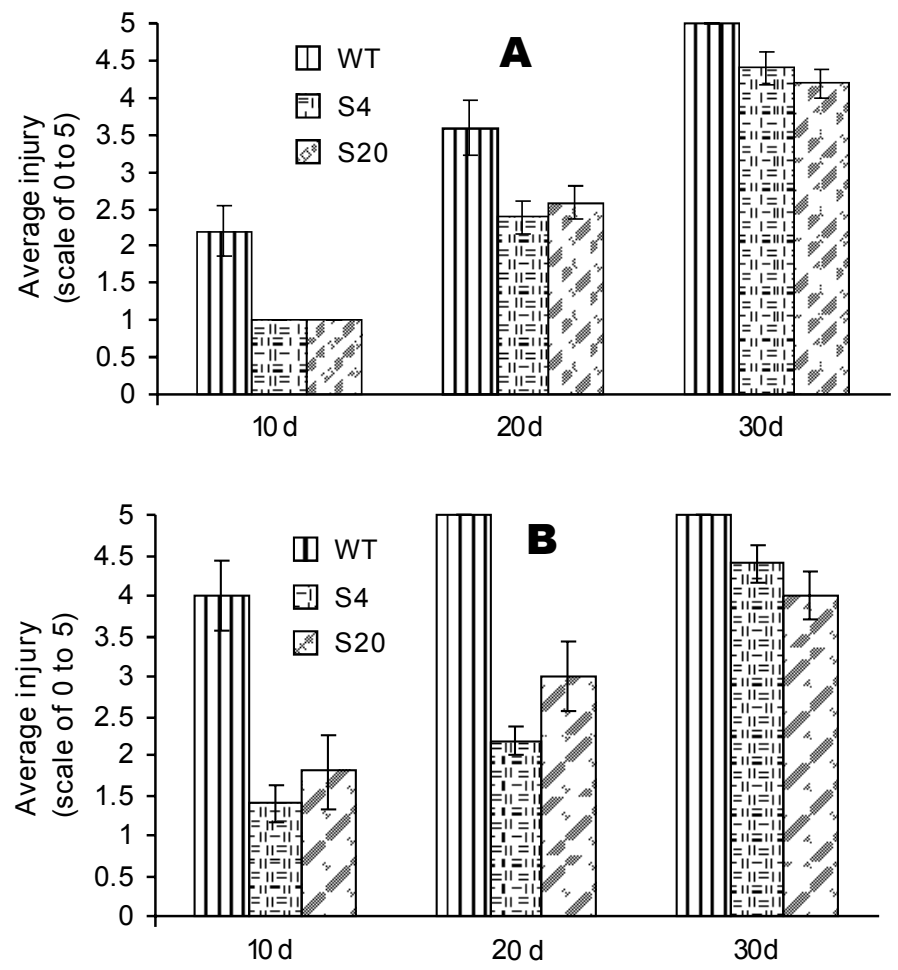

Fig. 7. Injury to wild-type (WT) and transgenic Mn-SOD (Lines S4, $\mathrm{S} 20$ ) tomato plants under stress from (A) $200 \mathrm{mM}$ or (B) $250 \mathrm{mM} \mathrm{NaCl}$ treatments after 10,20, and $30 \mathrm{~d}$. No visible injury $=0$; slow growth, and $<20 \%$ visible injury $=1$; yellowing leaves and $21-40 \%$ of leaf area with visible injury $=2$; wilted plants and $41-60 \%$ visible injury $=3$; seriously damaged plant unable to remain upright with $61-80 \%$ visible injury $=4$; dead plant or $>80 \%$ visible injury $=5$. Values are means $\pm \mathrm{SE}(\mathrm{n}=5)$. Different letters indicate significant differences $(P<$ 0.05 ) between means within each sampling time (Kruskal-Wallis test). *data for WT was also cited in Wang et al. (2005).

Our study indicated that transgenic tomato plants expressing the Mn-SOD gene from Havea displayed an enhanced tolerance to both MV and salt-induced oxidative stress. Transgenic plants had less electrolyte leakage than WT plants (Fig. 3), suggesting that overexpression of Mn-SOD in the transgenic plants reduced cellular damage caused by ROS (Bowler et al., 1991). After MV treatment, APX and SOD activity was higher in transgenic plants and was related to a plant's resistance to ROS damage (Allen, 1995; Van Camp et al., 1994).

An increase in ROS scavenging capacity is required to enable rapid removal of ROS produced during early seed imbibition (Gidrol et al., 1994). In this study, transgenic seeds were more tolerant to $\mathrm{NaCl}$ than WT seeds. The transgenic plants had higher SOD and APX activity, which could prevent the accumulation of $\mathrm{O}_{2}^{-}$and $\mathrm{H}_{2} \mathrm{O}_{2}$ concentration during the early stages of seed germination.

In our study, we found that shoot cuttings of transgenic tomato plants produced more root biomass than WT plants under salinity stress, indicating that overexpression of Mn-SOD enabled the transgenic plants to better deal with oxidative stress. Also, seedlings of transgenic $M n-S O D$ tomato plants showed less injury (Fig. 7) following $\mathrm{NaCl}(200 \mathrm{mM}$ and $250 \mathrm{mM})$ stress than WT plants. This is consistent with the theory that increased antioxidant enzyme activity can prevent $\mathrm{NaCl}$-induced oxidative stress (Fadzilla et al., 1997; Tanaka et al., 1999).

Our study showed that APX activity increased due to $\mathrm{NaCl}$ treatment and is consistent with other reports (Hernández et al., 
1999; Mittova et al., 2002; Sairam and Srivastava, 2002; Wang et al., 2005, 2006). This confirms earlier reports that APX plays an important role in scavenging $\mathrm{H}_{2} \mathrm{O}_{2}$ induced by $\mathrm{NaCl}$ stress. However, SOD activity decreased after $10 \mathrm{~d}$ of $\mathrm{NaCl}$ treatment (data not shown). The reason for this decrease in activity is not known but may be related to the long exposure to $\mathrm{NaCl}$.

In this study, the overexpression of $\mathrm{Mn}-\mathrm{SOD}$ in transgenic tomato plants enhanced seed germination, root development and seedling tolerance to $\mathrm{NaCl}$ stress. We conclude that increased antioxidant levels may play an important role in scavenging ROS when plants are exposed to salt stress.

\section{Acknowledgments}

We are grateful to the Washington Tree Fruit Research Commission for financial support. We also thank Dr. Lailiang Cheng (Cornell University; Ithaca, NY) for technical advice and assistance.

\section{References}

Allen, R.D. 1995. Dissection of oxidative stress tolerance using transgenic plants. Plant Physiol., 107: 1049-1054.

Alscher, R.G., N. Erturk and L.S. Heath, 2002. Role of superoxide dismutase (SODs) in controlling oxidative stress in plants. J. Exp. Bot., 53(372): 1331-1341.

Baek, K. and D.Z. Skinner, 2005. Differential expression of manganese superoxide dismutase sequence variants in near isogenic lines of wheat during cold acclimation. Plant Cell Rep., 25: 223-230.

Baek, K., D. Z. Skinner, P. Ling and X. Chen, 2006. Molecular structure and organization of the wheat genomic manganese superoxide dismutase gene. Genome, 49: 209-218.

Bowler, C., L. Slooten, S. Vandenbranden, R.D. Rycke, J. Botterman, S. Sybesma, M. Van Montagu and D. Inzé, 1991. Manganese superoxide dismutase can reduce cellular damage mediated by oxygen radical in transgenic plants. EMBO J., 10(7): 1723-1732.

Bowler, C., M. Van Montagu and D. Inzé, 1992. Superoxide dismutase and stress tolerance. Ann. Rev. Plant Physiol. Plant Mol. Biol., 43: 83-116.

Dionisio-Sese, M.L. and S. Tobita, 1998. Antioxidant responses of rice seedlings to salinity stress. Plant Sci., 135(1): 1-9.

Donahue, J.L., C.M. Okpodu, C.L. Cramer, E.A. Grabau and R.G. Alscher, 1997. Response of antioxidants to paraquat in pea leaves. Plant Physiol., 113: 249-257.

Doyle, J.J. and J.I. Doyle, 1987. Isolation of plant DNA from fresh tissue. Phytochem. Bull. Bot. Soc. Amer., 19: 11-15.

El-Saht, H.M. 1998. Responses to chilling stress in French bean seedlings: Antioxidant compounds. Bio. Plant., 41(3): 395-402.

Fadzilla, N.M., P.R. Finch and R.H. Burdon, 1997. Salinity, oxidative stress and antioxidant responses in shoot culture of rice. J. Exp. Bot., 48(307): 325-331.

Frary, A. and E.D. Earle, 1996. An examination of factors affecting the efficiency of Agrobacterium-mediated transformation of tomato. Plant Cell Rep., 16: 235-240.

Gidrol, X., W. Lin, N. Degousee, S.F. Yip and A. Kush, 1994. Accumulation of reactive oxygen species and oxidation of cytokinin in germinating soybean seeds. Eur. J. Biochem., 224(1): 21-28.

Gueta-Dahan, Y., Z. Yaniv, B.A. Zilinskas and G. Ben-Hayyim, 1997. Salt and oxidative stress: Similar and specific responses and their relation to salt tolerance in citrus. Planta, 203: 460-469.

Hernández, J.A., E. Olmos, F.G. Corpas, F. Sevilla and L.A. del Río, 1995. Salt-induced oxidative stress in chloroplasts of pea plants. Plant Sci., 105: 151-167.

Hernández, J.A., A. Campillo, A. Jimenez, J.J. Slarcon and F. Sevilla, 1999. Response of antioxidant systems and leaf water relations to $\mathrm{NaCl}$ stress in pea plants. New Phytol., 141: 241-251.
Hernández, J.A., A. Jimenez, P.M. Mullineaux and F. Sevilla, 2000. Tolerance of pea (Pisum sativum L.) to long-term salt stress is associated with induction of antioxidant defense. Plant Cell Environ., 23: 853-862.

Iannelli, M.A., F.V. Breusegem, M. Van Montagu, D. Inzé and A. Massacci, 1999. Tolerance to low temperature and paraquat-mediated oxidative stress in two maize genotype. J. Exp. Bot., 50(333): 523 532.

Jefferson, R., T. Kavanagh and M. Bevan, 1987. GUS fusions: Betaglucuronidase as a sensitive and versatile gene fusion marker in higher plants. EMBO J., 6: 3901-3907.

Khan, M.H. and S.K. Panda, 2002. Induction of oxidative stress in roots of Oryza sativa L. in response to salt stress. Biol. Plant., 45(4): 625-627.

Martinez, C.A., M.E. Loureiro, M.A. Oliva and M. Maestri, 2001. Differential responses of superoxide dismutase in freezing resistant Solanum curtilobum and freezing sensitive Solanum tuberosum subjected to oxidative and water stress. Plant Sci., 160: 505-515.

McKersie, B.D., S.R. Bowley and K.S. Jones, 1999. Winter survival of transgenic alfalfa overexpressing superoxide dismutase. Plant Physiol., 119: 839-847.

Miao, Z.H. and J.J. Gaynor, 1993. Molecular cloning, characterization and expression of Mn-superoxide dismutase from the rubber tree (Hevea brasiliensis). Plant Mol. Biol., 23: 267-277.

Mittler, R. and B.A. Zilinska, 1993. Detection of ascorbate peroxidase activity in native gels by inhibition of the ascorbate-dependent reduction of nitroblue tetrazolium. Anal. Bioch., 212: 540-546.

Mittova V., M. Tal, M. Volokita and M. Guy, 2002. Salt stress induces up-regulation of an efficient chloroplast antioxidant system in the salt-tolerant wild tomato species Lycopersicon pennellii but not in the cultivated species. Physiol. Plant., 115: 393-400.

Murashige, T. and F. Skoog, 1962. A revised medium for rapid growth and bioassay with tobacco tissue cultures. Plant Physiol., 15: 473-479.

Payton, P., R.D. Allen, N. Trolinder and A.S. Holaday, 1997. Overexpression of chloroplast-targeted $\mathrm{Mn}$ superoxide dismutase in cotton (Gossypium hirsutum L., cv. Corker 312) does not alter the reduction of photosynthesis after short exposures to low temperature and high light intensity. Photosynth. Res., 52: 233-244.

Perl, A., R. Perl-treves, S. Galili, D. Aviv, E. Shalgi, S. Malkin and E. Galin, 1993. Enhanced oxidative-stress defense in transgenic potato expressing tomato $\mathrm{Cu}, \mathrm{Zn}$ superoxide dismutases. Theor. Appl. Genet., 85: 568-576.

Rajguru, S.N., S.W. Banks, D.R. Gossett, M.C. Lucas, T.E. Fowler and E.P. Millhollon, 1999. Antioxidant response to salt stress during fiber development in cotton ovules. J. Cotton Sci., 3: 11-18.

Sairam, R.K. and G.C. Srivastava, 2002. Changes in antioxidant activity in sub-cellular fractions of tolerant and susceptible wheat genotypes in response to long -term salt stress. Plant Sci., 162: 897-904.

Scandalios, J.G. 1993. Oxygen stress and superoxide dismutase. Plant Physiol., 101: 7-12.

Shalata, A., V. Mittova, M. Volokita, M. Guy and M. Tal, 2001. Response of the cultivated tomato and its wild salt-tolerant relative Lycopersicon pennellii to salt-dependent oxidative stress: The root antioxidant system. Physiol. Plant., 112: 487-494.

Sreenivasulu, N., B. Grimm, U. Wobus and W. Weschke, 2000. Differential response of antioxidant compounds to salinity stress in salt-tolerant and salt-sensitive seedling of foxtail millet (Setaria italica). Physiol. Plant., 109: 435-442.

Tanaka, K., T. Hibino, Y. Hayashi, A. Tanaka, S. Kishitani, T. Takabe, S. Yokota and T. Takabe, 1999. Salt tolerance of transgenic rice overexpression yeast mitochondrial Mn-SOD in chloroplasts. Plant Sci., 148: 131-138.

Van Camp, W., H. Willekens, C. Bowler, M. Van Montagu, D. Inzé, P. Reupold-Popp, H. Sandermann and C. Langebartels, 1994. Elevated levels of superoxide dismutase protect transgenic plants against ozone damage. Bio/Tech.,12: 165-168. 
Wang, Y., M. Wisniewski, R. Meilan, M. Cui and L. Fuchigami, 2006. Transgenic tomato (Lycopersicon esculentum) that overexpress cAPX exhibits enhanced tolerance to UV-B and heat stress. J. Appl. Hort., 8(2): 87-90.

Wang, Y., M. Wisniewski, R. Meilan, M. Cui, R. Webb and L. Fuchigami, 2005. Overexpression of cytosolic ascorbate peroxidase in tomato (Lycopersicon esculentum L.) confers tolerance to chilling and salt stress. J. Amer. Soc. Hort. Sci., 130(2): 167-173.
Wisniewski, M., J. Sauter, L. Fuchigami and V. Stepien, 1997. Effects of near-lethal heat stress on bud break, heat-shock proteins and ubiquitin in dormant poplar (Populus nigra charkowiensis x P. nigra incrassata). Tree Physiol., 17(7): 483-450.

Zhu, J.K. 2000. Genetic analysis of plant salt tolerance using Arabidopsis. Plant Physiol., 124(3): 941-948. 